\title{
The Effect of Audio Visual Entrainment on Pre-Attentive Dysfunctional Processing to Stressful Events in Anxious Individuals
}

\author{
Guadalupe Villarreal Treviño, Ernesto Octavio López Ramírez*, \\ Guadalupe Elizabeth Morales Martínez, Claudia Castro Campos, \\ María Elena Urdiales Ibarra \\ Cognitive Science Laboratory, Department of Psychology, Universidad Autónoma de Nuevo León, \\ Monterrey, Mexico \\ Email: ${ }^{*}$ elopez42@att.net.mx
}

Received 19 August 2014; revised 19 September 2014; accepted 7 October 2014

Copyright (C) 2014 by authors and Scientific Research Publishing Inc.

This work is licensed under the Creative Commons Attribution International License (CC BY). http://creativecommons.org/licenses/by/4.0/

(c) (;) Open Access

\section{Abstract}

Experimental single case studies on automatic processing of emotion were carried on a sample of people with an anxiety disorder. Participants were required to take three Audio Visual Entrainment (AVE) sessions to test for anxiety reduction as proclaimed by some academic research. Explicit reports were measured as well as pre-attentive bias to stressing information by using affective priming studies before and after AVE intervention. Group analysis shows that indeed AVEs program applications do reduce anxiety producing significant changes over explicit reports on anxiety levels and automatic processing bias of emotion. However, case by case analysis of six anxious participants shows that even when all of the participants report emotional improvement after intervention, not all of them reduce or eliminate dysfunctional bias to stressing information. Rather, they show a variety of processing styles due to intervention and some of them show no change at all. Implications of this differential effect to clinical sets are discussed.

\section{Keywords}

Audio Visual Entrainment, Anxiety Disorders, Affective Priming, Single Case Experimental Study

\section{Introduction}

It is currently estimated that one in every four people (especially in the first world) suffers some kind of anxiety

*Corresponding author.

How to cite this paper: Treviño, G.V., Ramírez, E.O.L., Martínez, G.E.M., Campos, C.C. and Ibarra, M.E.U. (2014) The Effect of Audio Visual Entrainment on Pre-Attentive Dysfunctional Processing to Stressful Events in Anxious Individuals. Open Journal of Medical Psychology, 3, 364-372. http://dx.doi.org/10.4236/ojmp.2014.35038 
emotional disorder [1]. Moreover, it is forecasted that around the year 2020 this emotional disorder will occupy the second major health emotional problem in the world (perhaps the first in the second world countries). As a matter of fact, nowadays, anxiety mood disorders have become an important public health issue that affects 150 million people around the world [2]. Because of this the World Health Organization (WHO) has included the anxiety mood disorder in its mental health program as a priority.

Current emotion research trends are responding to this health issue by exploring three main questions [3]: What is the cause for an anxiety mood disorder? What are the reasons to maintain this mood disorder? And what are the necessary clinical approaches to eliminate an anxiety mood disorder?

From a cognitive point of view, mood disorders relate to dysfunctional emotion information processing [4]. For instance, it has been suggested that anxiety mood disorders activate dysfunctional emotion appraisal mechanism based on fear whereas depression is based on dysfunctional processing of sadness regarding feelings of lost and fail [5]. Specifically, academic reports suggest that anxiety mood disorders are based on pre-attentive automatic processing appraisal promoting dysfunctional biased attention to stressors [4] [6] [7] whereas depression mood disorders are based on sustained attention to dysfunctional self-biographic information stored in patient's memory [4] [8]-[11].

Cognitive clinical interventions claim for many patients successfully recovering from anxiety and depression disorders [12] [13]. However, there is still much to learn before we can claim that we know the answer to what maintains and eliminates a mood disorder. In order to do this much more research analytical power is needed to empower theoretical explanation. Alternative empirical research directions have been suggested to this purpose. For instance, Hedlefs et al. [14] suggest that by combining standard experimental paradigms (affective priming techniques) with standard anxiety disorder tests, powerful insights can be obtained about how clinical intervention affects stressed cognitive-emotion functioning. Specifically, these authors show that even when a patient explicitly claims to be fully recovered from anxiety and these claims are supported by low test anxiety scores there is still the possibility of having a dysfunctional automatic bias to process stressors. Specific ways on how clinical intervention affects perverse dysfunctional cognitive-emotion mechanisms are beyond the traditional anxiety tests and standard diagnostic to anxiety can be benefited by this combined approach to determine the impact of clinical intervention.

Indeed many proclaimed ways to mood disorder clinical intervention are of interest since these can be now used to determine their specific effect over dysfunctional automatic appraisal mechanisms underlying a mood disorder. Specifically, an area of special scientific interest to the current study is the Audio Visual Entrainment (AVE) approach to treat mood disorders. Allegedly, this approach postulates that by inducing specific brainwave activity in patients with a mood disorder, recovery from disease is possible [15] [16]. Since 1959 John Barrow's discovery that brain EEG activity can be systematically affected by specific audio-visual stimuli patterns and a growing academic interest on how the brain activity can be synchronized by audio-visual entrainment have led to a burst of academic studies in this topic (for a review see [17]-[19]). Therapeutic Specific instances of AVE can be found on jet lag and seasonal depression [20], pain control [21] [22] and anxiety mood disorders [16] [23].

It is well known that different mood states relate to specific brain waves [24] [25]. In regard to anxiety, the brain's natural response to stress is a decrease of Brainwave Alpha activity and an increase in Brainwave Beta activity. The higher the stress level, the faster the frequency. Thus, severe stress levels are normally reflected in high Beta wave frequencies (Beta 2: $20 \mathrm{~Hz}-40 \mathrm{~Hz}$ ).

The purpose of considering an AVE intervention in this study is to affect anxious people's brain wave activity (supposedly Beta 2) through repetitive auditory and visual stimulation at specific frequencies to enhance Brainwave Alpha activity (relax mood states at $8 \mathrm{~Hz}-12 \mathrm{~Hz}$ [15] [21]). Briefly, an AVE intervention is a technique using flashing lights through a pair of specially designed glasses and pulses of tones through headphones. After a systematic stimulation program (e.g. several sessions of 30 minutes), the brain will synchronize its EEG according to a provided AVE frequency/amplitude signal.

Flourishing of AVE research has seemed to significantly decrease since the year 2000 . New research trends are on demand and the purpose of the current paper is to provide a new research empirical direction as well as to suggest an alternative form to clinical assessment of mood disorder recovery. Thus, rather than considering AVE only for brain synchronization, here it is argued that AVE can be used to guide specific ways of cognitive processing. In doing so, it is hypothesized that therapeutic AVE to reduce anxiety problems [15] [19] combined with affective priming experimental techniques (as in Hedlefs et al. [14]) do empower research to determine 
how an AVE intervention affects elimination of automatic dysfunctional appraisal underlying mood disorders. If explicit reports of recovery from an anxiety mood disorder due to AVE intervention agree with specific patterns of cognitive emotion processing, then brain synchronization will allow exploration on our own emotional nature, otherwise exploration results with this combined method will show limitations of AVE approach to heal mood disorders. This is a win-win situation and the following studies show initial research in this direction.

\section{Method}

A set of cognitive science of emotion studies were carried out to test how Audio Visual Entrainment (AVE) intervention affects anxious people's dysfunctional automatic emotion processing of stressful events. First an affective priming study was implemented to determine if typical individuals pre-attentively automatically recognized selected stressful words as different to other emotion words pairs. Then, in second affective priming study recognition latencies to these stressful words coming from people having an anxiety disorder were compared against typical performances to identify participant with biased dysfunctional processing to stressful events. Finally, a third study tried to identify what was the effect on AVE intervention on the way people with an anxiety disorder automatically process stressful information. Overall, the goal is to show how the affective priming technique allows visualizing the effects that an AVE intervention has over people dysfunctional processing to stressful situations in a way that cannot be reported by standard tests of anxiety.

\subsection{Participants}

A first sample of 84 healthy psychology bachelor Mexican students (48 women, 36 men) participated in a study to test for recognition of stressful words (calibration). Their age interval varied between 18 and 25 years old. The inclusion criterion was that they showed no anxiety disorder (see next session) and they had the same social context from the other next two study participants. In a second study designed to test for dysfunctional automatic processing bias to recognize stressful words a new sample of 20 out of 150 psychology bachelor Mexican students who obtained very low I.S.R.A. anxiety scores [26] was considered the control group whereas 6 out of 224 students who obtained the highest I.S.R.A. anxiety scores conformed the experimental group. Finally, an AVE intervention study considered a sample of six persons selected from the second study who were diagnosed with an anxiety disorder as well as showing dysfunctional automatic processing bias to stressful words.

\subsection{Instruments}

The validated Spanish version for the Inventory of Situations and Responses of Anxiety (I.S.R.A.) [26] [27] was used to differentiate a participant who had an anxiety disorder from those who had not this emotional condition. This inventory tries to assess the general level of anxiety by presenting 22 regular stress scenarios (not extreme) where participants had two express how often such scenery make them anxious by using 24 Likert scale responses ( 7 cognitive, 10 physiological, and 7 motor).

In order to test automatic cognitive-emotion processing an affective priming study was implemented to compare automatic recognition times of emotional words against stressful words' recognition latencies. The affective priming paradigm began as an experimental technique presented by Fazio [28] to study how the emotional valence of a stimulus (prime) affects the recognition of other valenced stimuli (targets). The affective priming effect has proven to be a robust psychological effect and it has been tested by using a wide variety of stimuli [29].

Regarding AVE intervention over selected participants, the DAVID DELIGHT PRO system [19] [22] complained with the necessary experimental requirements. Specifically, this instrument produce the harmonics that square wave stimulation does but will not produce entrainment-induced anxiety (people prone to anxiety are susceptible to having an anxiety or panic reaction to square wave stimulation) while stimulating in the alpha ranges (by using sinusoidal waves stimuli [30]).

\subsection{Stimuli}

The affective priming experimental stimuli used combinations of emotional congruent word pairs (Positive/ Positive, Negative/Negative, Stress/Stress and Neutral/Neutral). Word pairs used to create the experimental stimuli set are presented in Table 1. Word size as well as word frequency (by using the LEXEXP Spanish word dictionary) were controlled. Positive, Negative and neutral words are taken from standard affective priming 
Table 1. Emotional words used to create the affective priming word pairs stimuli.

\begin{tabular}{cccc}
\hline POSITIVE & NEGATIVE & ANXIETY & NEUTRAL \\
\hline HAPPINESS-SMILE & FEAR-TERROR & INSECURE-HUMILIATE & TABLE-LAKE \\
JOY-PRETTY & ANGER-TORTURE & AFRAID-REJECTION & PLATE-SOCK \\
LOVE-ACHIEVE & RANCOUR-DAMAGE & EXAM-DENTIST & WINDOW-SOUP \\
ENTHUSIASM-BRILLIANT & EVIL-CRYING & WORK-INJECTION & CLOUD-STONE \\
HOPE-JOYFUL & SADNESS-DISCOMFORT & DATE-ERROR & BOAT-TENIS \\
GIFT-AFFECTION & FAIL-HIT & DECISION-FUTURE & PENCIL-ICE \\
ILLUSION-SKILLFUL & DEPRESSION-DEATH & PROBLEM-CROWD & COFFEE-LIGHT \\
WIN-LOYAL & AGGRESSION-DEFEAT & ARGUE-VIOLENCE & BOOK-WATER \\
BEAUTY-HUG & DISAPPOINTMENT-BLOOD & OBSERVER-SWEAT & WOOD-COW \\
KIND-DETAIL & DROWN-LIE & PUBLIC-TENSE & ERASE-ONION \\
\hline
\end{tabular}

experiments [29]. Stress words were selected from the I.S.R.A. inventory by three judges whose research is related to cognition and emotion.

Mood incongruent word pairs are relevant to this study because they allowed inspection about how emotion primes contribute to emotion valence recognition of a target. Relevant to this study are contributions of positive and negative primes to recognition of words describing stressful events.

Mood incongruent word pairs are relevant to this study because they allowed inspection about how emotion primes contribute to emotion valence recognition of a target. Relevant to this study are contributions of positive and negative primes to recognition of words describing stressful events.

\subsection{Procedure}

First affective priming was implemented tested if typical individuals (first sample) recognized stressful word pairs as emotional different from standard emotion congruent word pairs (Calibration phase). Here, each subject attended to a 60 minutes individual session with a trained researcher. Each sat in front of a computer and instructions were provided until they understood the experimental cognitive task very well. The experimental trails were as follows. First, a point at the center of the computer screen appeared to allocate participant's gaze at the center of the computer screen. Then, a word with or without emotion appeared for 250 milliseconds followed by a white interval of 50 milliseconds. Finally, another word with or without emotion appeared and stayed at the computer screen until the participant decided if this last word was emotional or neutral. The computer user had to press the letter " $Z$ " in the computer keyboard that had a red paper on it with the "YES" word written on it to indicate the word was emotional or to press the letter "M" that had a green paper that had the "NO" word if the presented word had no emotion (valence identification task).

The second study sought to look for dysfunctional automatic emotion processing to stress word pairs by anxious people (experimental group). Here, the experimental group's performance through an affective priming experimental conditions (like in the first study) was compared against a group with very low stress scores (control group) in order to identify participants with severe dysfunctional automatic processing bias to stress word pairs. The affective priming study procedure was the same as in the first study.

Finally, the third sample (six anxious people) participated in an AVE intervention. In this occasion each participant was scheduled separately through individual sessions. They were required to take the same affective priming study shown in the second study before and after the AVE intervention to test for stress words' latencies. The AVE intervention consisted in using the DAVID LIGHT PRO (DLP) instrument twice a week during three weeks. Practice time (15 minutes) was provided the first time such that participants got familiar with the instrument. In each intervention the participant used the DLP headphones and glasses in an isolated environment and was exposed during 30 minutes to stimuli to achieve Alfa wave brain synchronization (DLP's Program 3).

\section{Results}

Regarding the stimuli calibration phase, a repeated measure ANOVA was carried on over emotion word pairs' 
latencies. All participants were included since they provided more than $90 \%$ correct latencies. As expected, the results showed a significant main effect for the type of word relation factor, $F(3,249)=18.797, p=0.00000$, $\eta_{\mathrm{p}}^{2}=0.184650$. Regarding recognition of stress related word pairs an analytical post hoc comparison showed significantly slower recognition latencies than the rest of emotion word pairs $F(1,83)=34.174, p=0.0000$. Figure 1 shows participants' performance through all of the experimental conditions. It can be observed from the graph that participants discriminate between emotions and neutral information and that they seem to use more cognitive resource to valuate stress information.

After stress words were recognized as significantly different from other emotion congruent words, a mixed ANOVA was carried on over emotion word pairs' latencies. All participants were included since they provided more than $90 \%$ correct latencies. In this analysis a marginal significant difference is obtained between both groups $\mathrm{F}(1,24)=4.091, \mathrm{p}=0.0543$ and again as it was expected, the results showed a significant main effect for the type of word relation factor, $\mathrm{F}(2,48)=13.412, \mathrm{p}=0.0000, \eta_{\mathrm{p}}^{2}=0.358$. An analytical comparison show that the group performance difference was due to emotion recognition differences of stress word pairs $\mathrm{F}$ $(1,24)=4.638, \mathrm{p}=0.0415$ (see Figure 2).

Thus it is important to emphasize from the above results that anxious people's significant higher latencies to automatically process stressful events imply consuming more cognitive resources to analyze this kind of information. In turn it is assumed that this cognitive appraisal mechanism helps to maintain a dysfunctional mood state [4]-[9].

Finally, over the third study data a 2 (Intervention time) $\times 4$ (Emotion relation) mixed ANOVA was carried over pooled correct answers. None of the students presented more than $5 \%$ response errors. As expected results showed a significant main effect for the type of emotion relation $F(3,30)=6.0834, p=0.0023, \quad \eta_{\mathrm{p}}^{2}=0.378$. Regarding intervention time, results only showed a significant performance difference to recognize stressful events. This is confirmed by an analytical comparison between pre-post stress word recognition latencies $\mathrm{F}$ ( 1 , $10)=5.334, p=0.0435$ and by a significant interaction $F(3,30)=2.7191, p=0.06204$ that can be visualized in Figure 3.

The above results suggest a relevant AVE Intervention capable of affecting even perverse automatic processing bias to stressful events. However, a case by case analysis shows this is not always true. Thus, Figure 4

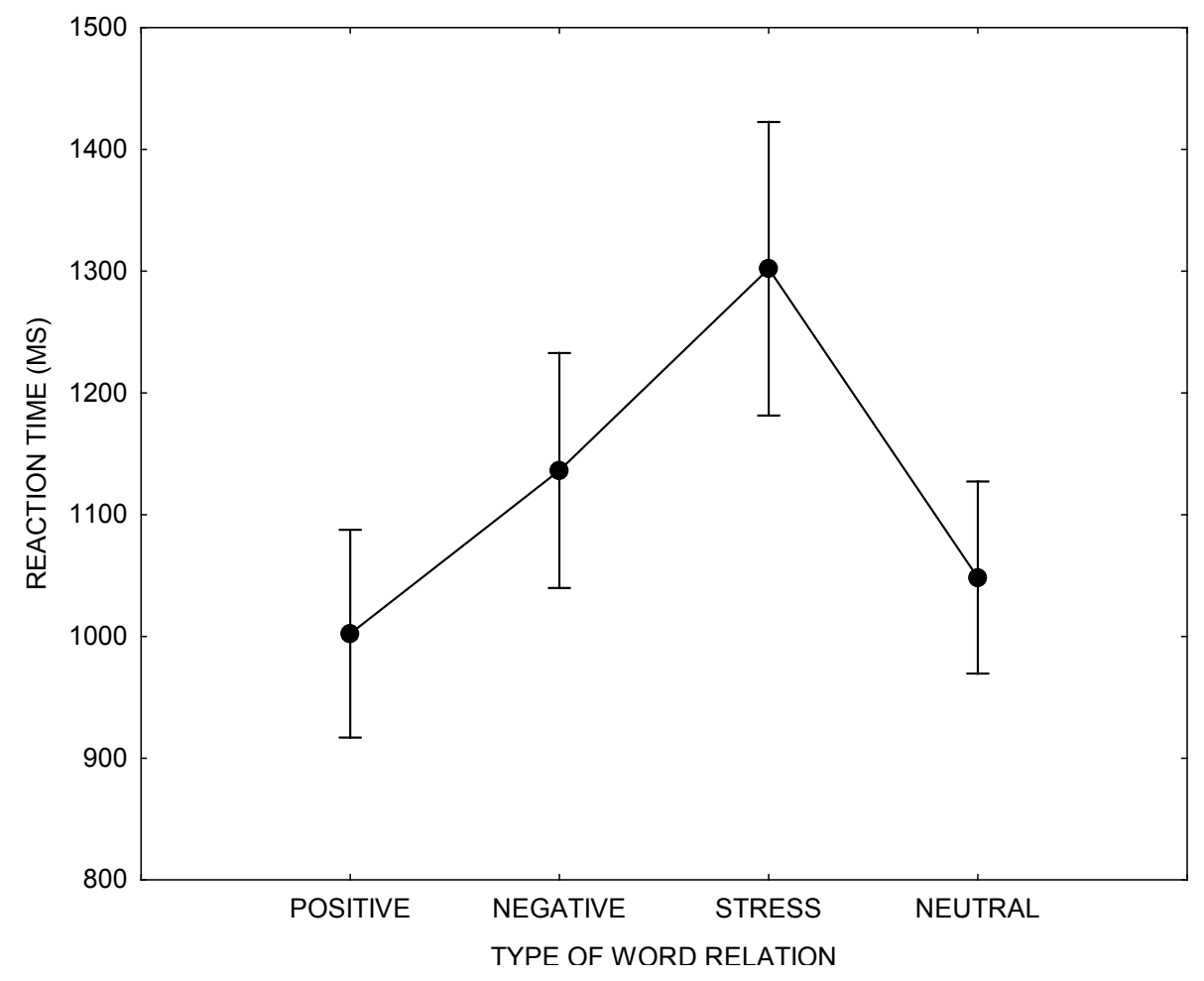

Figure 1. Participants recognized stress words as an emotional different set from other emotion and non-emotional words. 


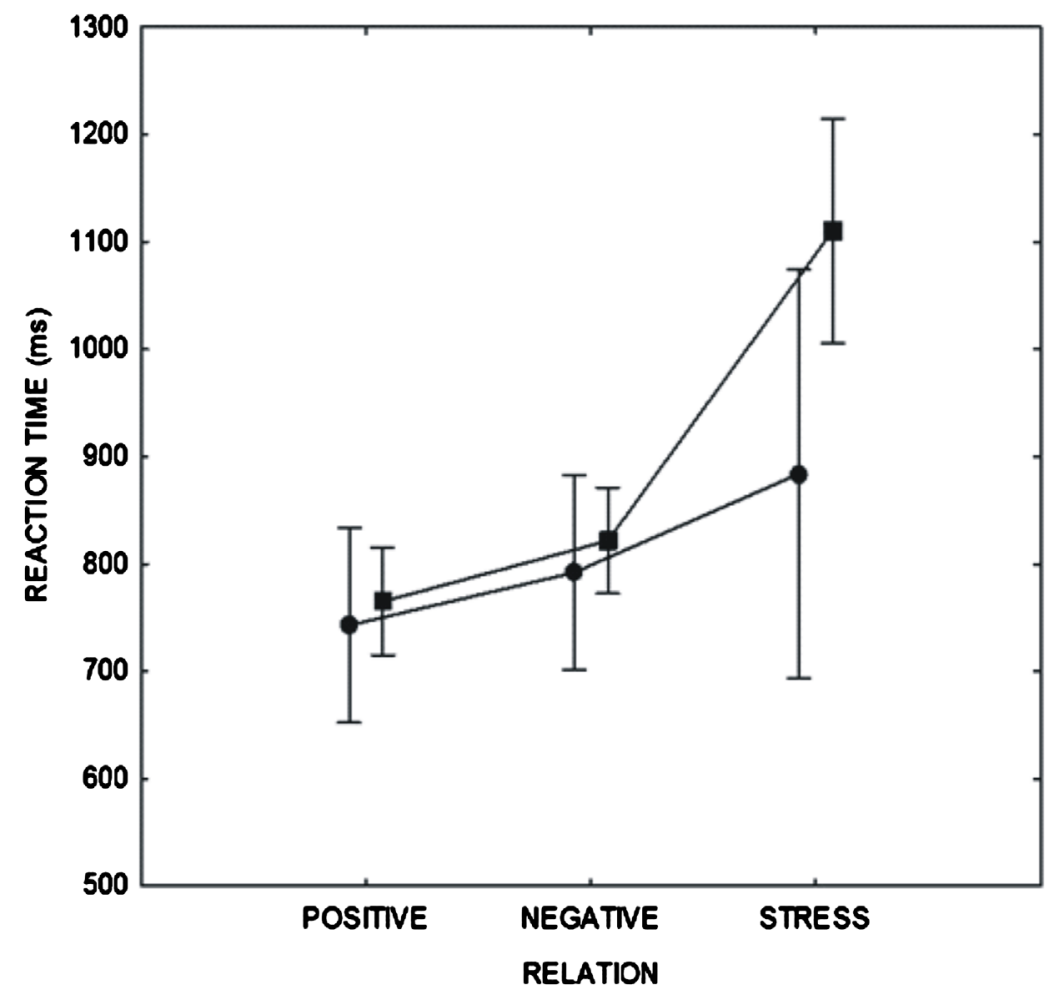

Figure 2. The interaction graph shows recognition differences of stressful events between typical individuals and people with anxiety.

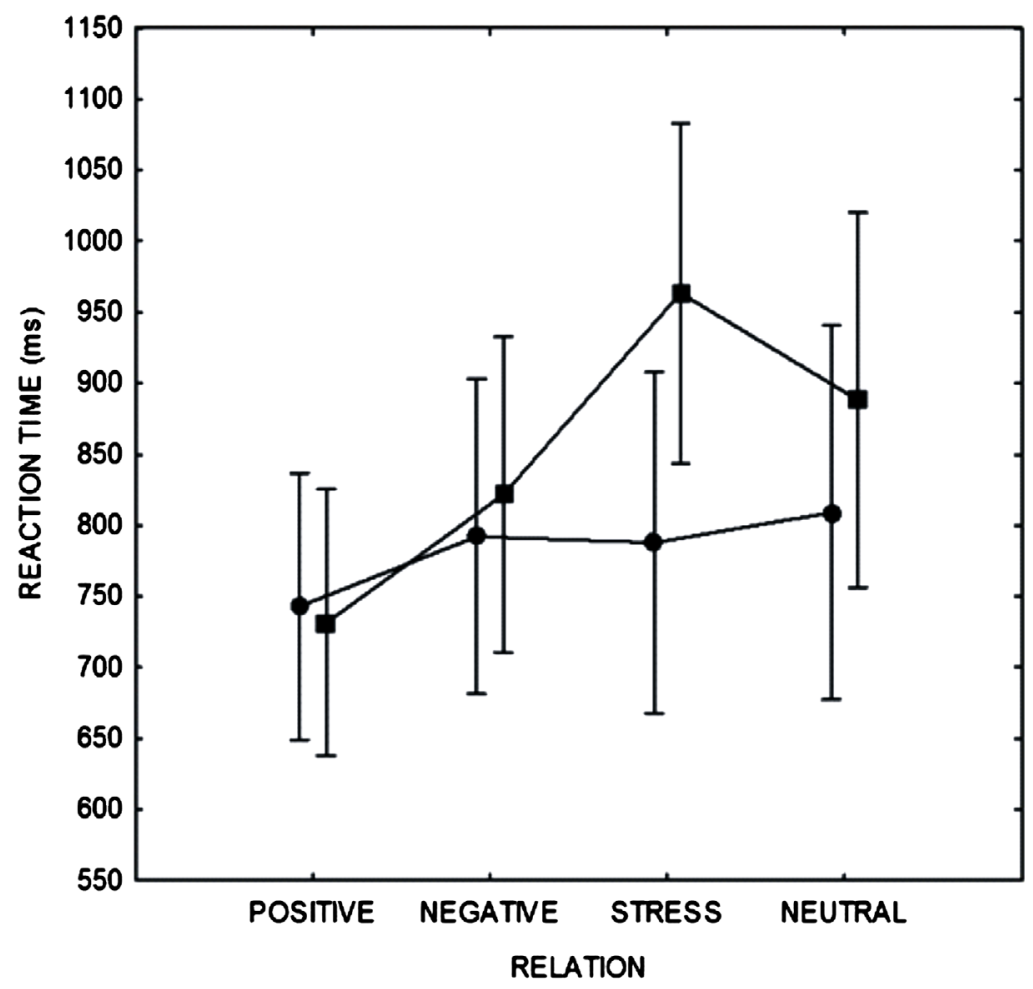

Figure 3. Interaction graph showing response latencies to all affective priming experimental conditions before and after AVE intervention. 


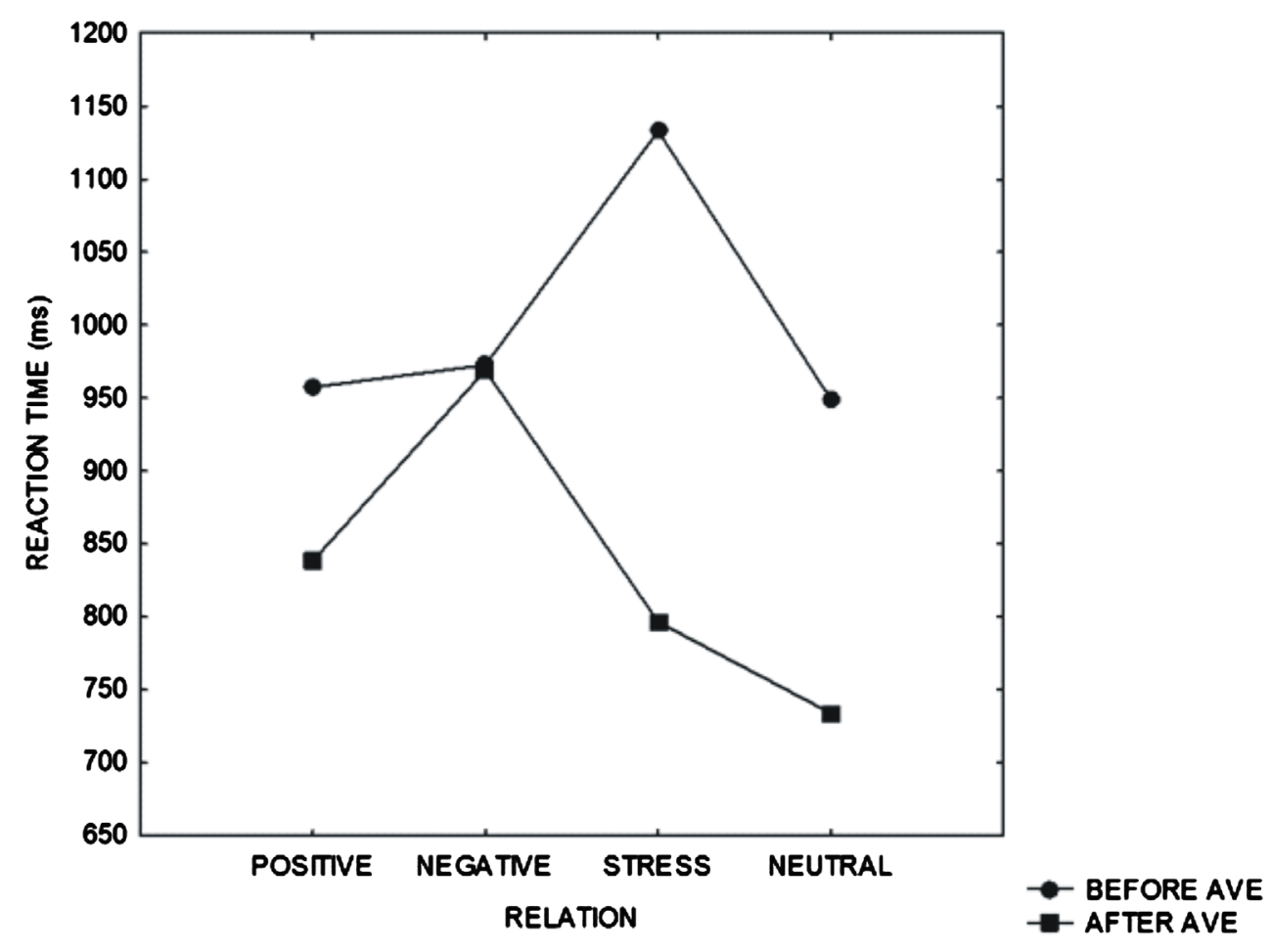

Figure 4. Interaction graph showing how AVE decreased automatic processing bias to stressful events in a patient who reports recovery from an anxiety mood disorder.

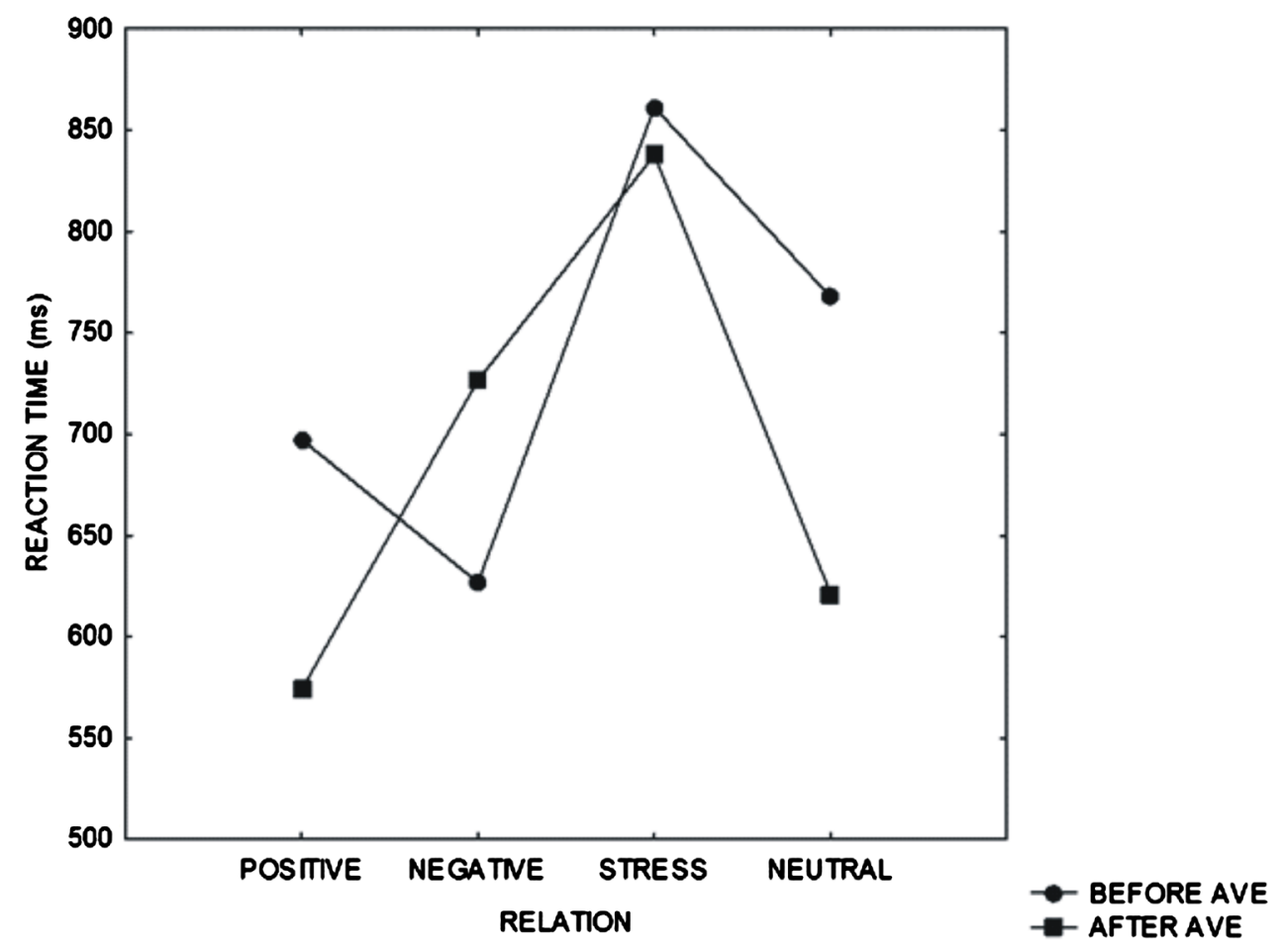

Figure 5. Interaction graph showing no AVE effect on automatic processing bias to stressful events.

shows the case for a successful AVE intervention where the participant reported complete recovery from his chronic anxiety disorder. However, Figure 5 shows results for an anxious patient who reported no benefits to 
her emotional disorder by using AVE. Interestingly enough; there was a participant who reported complete recovery but maintained automatic processing bias to stressful events.

\section{Discussion}

As the current results suggest, the constant claim that AVE produces recovery from an anxiety disorder must be taken into account carefully. Here, two main observations emerge. First, single case analysis [31] through affective priming methods (ANOVA designs; [32]) is necessary to detect boundaries or limitations of this kind of intervention on dysfunctional biased automatic processing of stressful events. This is supported by the fact that a patient who has reported recovery from an AVE intervention and obtained low anxiety scores do indeed maintain dysfunctional bias to process stressful information. Elimination of this bias to stress information is necessary for recovery (Williams et al., 1997) [3] and its disappearance if not frequently detected by conventional anxiety tests [14]. Second, it is clear from the study results that AVE intervention is capable to affect dysfunctional automatic appraisal to stressful information. This is relevant to cognition and emotion research as well as to AVE research since this approach encourages experimental manipulation to widen our understanding on mood disorders. For instance, it is not clear why some anxious people do respond to AVE intervention (e.g. Figure 4) and others do not (e.g. Figure 5).

Follow up research surely will provide valuable information on how manipulation of frequency/amplitude stimuli through AVE has limitations on mood disorder recovery and it will hypothesize formulation of brain synchronization and automatic dysfunctional appraisal to stressful events in anxious people.

\section{References}

[1] Kessler, R.C., Gruber, M., Hettema, J.M., Hwang, I., Sampson, N. and Yonkers, K.A. (2008) Co-Morbid Major Depression and Generalized Anxiety Disorders in the National Comorbidity Survey Follow Up. Psychological Medicine, 38, 365-374. http://dx.doi.org/10.1017/S0033291707002012

[2] Parker, G. (2002) Dealing with Depression: A Commonsense Guide to Mood Disorders. Allen \& Unwin, Crows Nest.

[3] Williams, J.M.G., Watts, F.N., MacLeod, C. and Mathews, A. (1997) Cognitive Psychology and Emotional Disorders. 2nd Edition, Wiley, Chichester.

[4] Power, M.J. and Dalgleish, T. (2008) Cognition and Emotion: From Order to Disorder. 2nd Edition, Psychology Press, New York.

[5] Matthews, G. and Wells, A. (2000) Attention, Automaticity, and Affective Disorder. Behavior Modification, 24, 69-93. http://dx.doi.org/10.1177/0145445500241004

[6] Mathews, A. and Milroy, R. (1994) Processing of Emotional Meaning in Anxiety. Cognition and Emotion, 8, 535-553. http://dx.doi.org/10.1080/02699939408408958

[7] Matthews, G. and Wells, A. (2000) The Cognitive Science of Attention and Emotion. In: Dalgleish, T. and Power, M., Eds., Handbook of Cognition and Emotion, Wiley, Nueva York, 171-190.

[8] Power, M.J. and Dalgleish, T. (1998) Cognition in the Context of Emotion: The Case of Depression. In: Quelhas, A.C. and Pereira, F., Eds., Cognition and Context, Instituto Superior de Psicología Aplicada, Lisboa, 381-413.

[9] Dalgleish, T., Taghavi, R., Doost, H.N., Moradi, A., Yule, W. and Canterbury, R. (1997) Information Processing in Clinically Depressed and Anxious Children. Journal of Child Psychology, Psychiatry, 38, 535-541. http://dx.doi.org/10.1111/j.1469-7610.1997.tb01540.x

[10] Siegle, G.J. (1999) Cognitive and Physiological Aspects of Attention to Personally Relevant Negative Information in Depression. Doctoral Thesis, San Diego State University, San Diego.

[11] Siegle, G.J. (2001) A Neural Network Model of Attentional Biases in Depression. In: Reggia, J. and Ruppin, E., Eds., Disorders of Brain, Behavior and Cognition: The Neurocomputational Perspective, Elsevier, Amsterdan, 415-441.

[12] Sudak, D.M. (2006) Cognitive Behavioral Therapy for Clinicians: Psychotherapy in Clinical Practice. Lippincott Williams \& Wilkins, Philadelphia.

[13] Wond, F.W. and Dryden, W. (2002) Handbook of Brief Cognitive Therapy. John Wiley \& Sons, West Sussex.

[14] Hedlefs, A.M.I., Lopez, R.E.O. and Antona, C.C.J. (2010) Social Anxiety Assessment through Self Report and Automatic Processing of Emotional Information. In: García, C.H., Ed., Hispanic Psychology Yearbook, Nova Science Pub Inc., Hauppauge, 167-176.

[15] Siever, D. (2007) Audio-Visual Entrainment: History, Physiology and Clinical Studies. In: Evans, J.R., Ed., Handbook of Neurofeedback: Dynamics and Clinical Applications, The Haworth Medical Press, New York, 155-183. 
http://dx.doi.org/10.1201/b14658-11

[16] Siever, D. (2012) Audio-Visual Entrainment: Finding a Treatment for Post-Traumatic Stress Disorder. Self-Published Paper. www.mindalive.com

[17] Oster, G. (1973) Auditory Beats in the Brain. Scientific American, 229, 94-102. http://dx.doi.org/10.1038/scientificamerican1073-94

[18] Donker, D., Njio, L., Van Leewan, W.S. and Wieneke, G. (1978) Interhemispheric Relationships of Responses to Sine Wave Modulated Light in Normal Subjects and Patients. Encephalography and Clinical Neurophysiology, 44, 479489. http://dx.doi.org/10.1016/0013-4694(78)90032-9

[19] Siever, D. (2003) Audio-Visual Entrainment: History and Physiological Mechanisms. Biofeedback, 31, 21-27.

[20] Berg, K. and Siever, D. (2009) A Controlled Comparison of Audio-Visual Entrainment for Treating Seasonal Affective Disorder. Journal of Neurotherapy, 13, 166-175. http://dx.doi.org/10.1080/10874200903107314

[21] Padmanabham, R., Hildreth, A.J. and Laws, D. (2005) A Prospective, Randomized, Controlled Study Examining Binaural Beat Audio and Pre-Operative Anxiety in Patients Undergoing General Anesthesia for Day Case Surgery. Anaesthesia, 60, 874-877. http://dx.doi.org/10.1111/j.1365-2044.2005.04287.x

[22] Siever, D. (2003) Audio-Visual Entrainment: Dental Studies. Biofeedback, 31, 29-31.

[23] Leonard, K., Telch, M. and Harrington, P. (2000) Fear Response to Dissociation Challenge. Anxiety, Stress and Coping, 13, 355-369. http://dx.doi.org/10.1080/10615800008248341

[24] Raymond, J., Varney, C., Parkinson, L.A. and Gruzelier, J.H. (2005) The Effects of Alpha/Theta Neurofeedback on Personality and Mood. Cognitive Brain Research, 23, 287-293. http://dx.doi.org/10.1016/i.cogbrainres.2004.10.023

[25] Shealy, N., Cady, R., Cox, R., Liss, S., Clossen, W. and Veehoff, D. (1989) A Comparison of Depths of Relaxation Produced by Various Techniques and Neurotransmitters Produced by Brainwave Entrainment. Shealy and Forest Institute of Professional Psychology, A Study Done for Comprehensive Health Care, Unpublished.

[26] Tobal, J.J.M. and Vindel, A.C. (1986) Inventario de situaciones y respuestas de ansiedad I.S.R.A. TEA, Madrid.

[27] Tobal, J.J.M. and Vindel, A.C. (1988) Inventario de situaciones y repuestas de ansiedad. 2da Edición revisada con la inclusión de rasgos específicos, TEA, Madrid.

[28] Fazio, R.H. (2001) On the Automatic Activation of Associated Evaluations: An Overview. Cognition and Emotion, 75, 115-141. http://dx.doi.org/10.1080/02699930125908

[29] Klauer, K.C. and Musch, J. (2003) An Affective Priming: Findings and Theories. In: Musch, J. and Klauer, K., Eds., The Psychology of Evaluation: Affective Processes in Cognition and Emotion, Lawrence Erlbaum Associates Publishers, Mahwah, 7-50.

[30] Cvetkovic, D., Simpson, D. and Cosic, I. (2006) Influence of Sinusoidally Modulated Visual Stimuli at Extremely Low Frequency Range on the Human EEG Activity. Proceedings of the Annual International Conference of the IEEE Engineering in Medicine and Biology Society, New York, 31 August-3 September 2006, 213-216.

[31] Kazdin, A. (1982) Single-Case Research Designs. Oxford University Press, New York.

[32] Anderson, N. (2001) Empirical Direction in Design and Analysis: Scientific Psychology Series. LEA, Mahwah. 
Scientific Research Publishing (SCIRP) is one of the largest Open Access journal publishers. It is currently publishing more than 200 open access, online, peer-reviewed journals covering a wide range of academic disciplines. SCIRP serves the worldwide academic communities and contributes to the progress and application of science with its publication.

Other selected journals from SCIRP are listed as below. Submit your manuscript to us via either submit@scirp.org or Online Submission Portal.
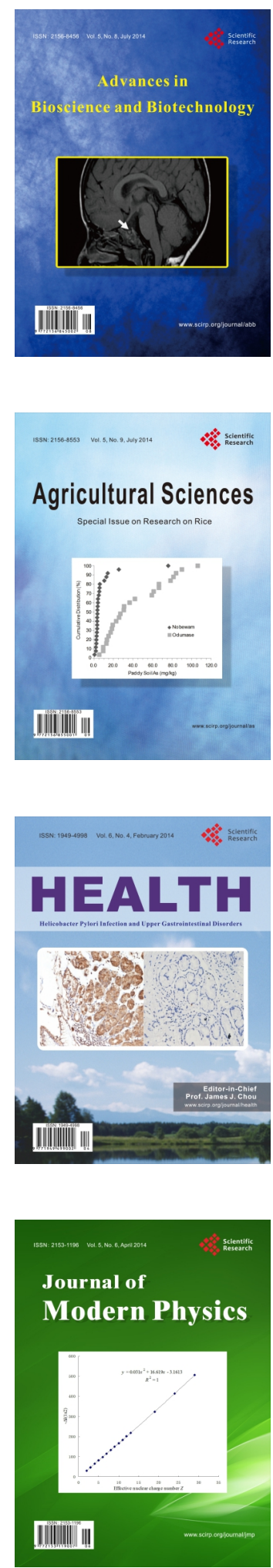
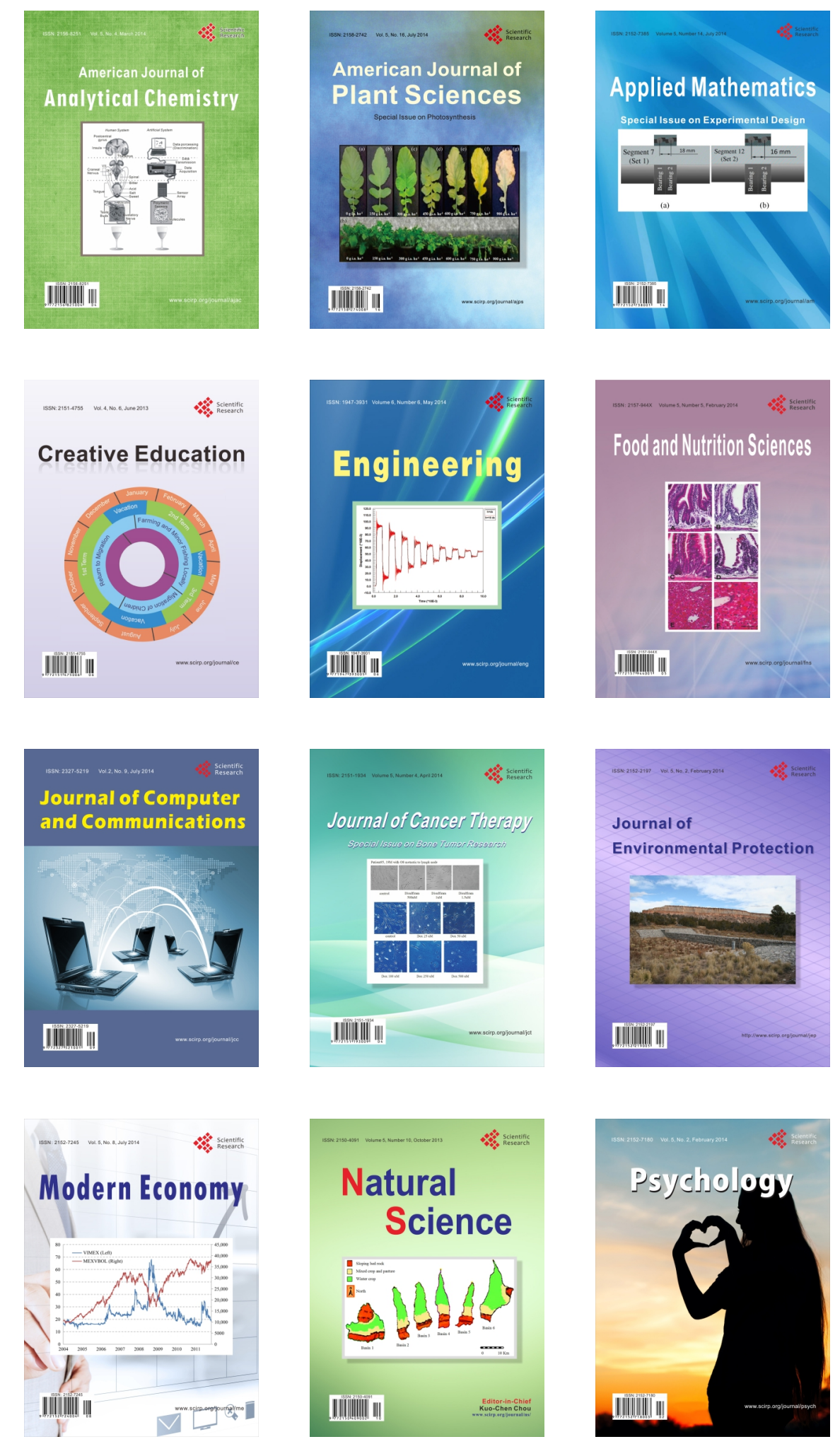